\title{
Recognizing Multiple Decision-making Models: A Guide for Managers
}

\section{Joan Giesecke}

\begin{abstract}
Empirical studies of decision making find that the process is more disorderly than described in rational models. New models have appeared that suggest that managers need to accommodate the randomness found in complex organizations. This article examines two approaches for dealing with this disorder: the political-bargaining model and the garbage can model. The essay clarifies the differences between these two approaches and assesses their usefulness to managers for understanding the decision-making process.
\end{abstract}

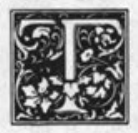

he decision-making process in academic libraries is becoming more complex and confusing as the environment for the organizations becomes more ambiguous. Academic library managers face the particularly difficult challenge of trying to understand and manage the decision-making process at a time when the university environment is changing, the information delivery mechanisms are in flux, and the economic climate is unstable. This environment for the library can be described as an organized anarchy where goals are ambiguous, organizational processes are unclear, and fluid participation in the decision-making process exists. Nonetheless, within this setting, decision making remains a primary task for managers who must now understand not only the content of the decisionmaking choice but also the context in which the decision is being made. Managers must be able to recognize which decision-making methods are being employed if they wish to understand and influence the process. This is because the method used affects what alternatives are considered, determines who can participate in the process, and influences how choices are made. Managers must be able to analyze accurately the decision-making context if they are to employ effective strategies for guiding the process to a successful conclusion.

Although the models for decision making developed in the fields of sociology, organizational development, and management are applicable to the academic library environment, researchers have found that the reality of decision making is more chaotic than many of the models assume. In fact, in such complex organizations as academic libraries, more than one decision-making method may be used in any given situation.

This article begins with a theoretical overview of three major decision-making models which are applicable to the library environment: the rational model, the political-bargaining model, and the garbage can model. Next, a framework for identifying two of the models of decision making, the political-bargaining model and the garbage can model, is presented. These two models were chosen for the

Joan Giesecke is Associate Dean for Collections and Services at University Libraries, University of Nebraska, Lincoln, Nebraska 68588-0410. 
study because they developed as alternatives to the rational model, have been presented as more realistic than the rational model, and because clear guidelines had not been developed to help managers distinguish between these two methods. This framework is then tested in a case study set in an academic library to determine if the framework can help managers distinguish among decision-making methods. Finally, strategies for library managers to use for effectively working within these processes are provided.

\section{THEORETICAL FRAMEWORK}

Decision making became a subject in its own right at the turn of the century, when administrators sought ways to respond to the growing complexity of their political arena. During this early period, the management literature tried to improve decision making by applying more rational procedures. As James Burns notes, "Classical thinking about decision making has viewed the process as an essentially orderly and rational one. A problem is defined and isolated; information is gathered; alternatives are set forth; an end is established; means are created to achieve that end; a choice is made."1 Managers were urged to maximize the values of efficiency and economy. The rational model was part of a broad orthodoxy that emphasized scientific principles of management, a scientific approach to personnel management, and budgeting as an instrument of rationality, coordination, and control. The rational model of decision making offered an impartial scientific process for decision making and was reinforced by the success of operations research and systems analysis techniques during World War II. ${ }^{2}$

In spite of this prescriptive emphasis, studies of how decisions were actually made in complex organizations showed that, in practice, the process was not as orderly as the models assumed. Rather, it appears that decision making is a messy, disorderly process and, hence, is difficult to describe and analyze. ${ }^{3}$

Two models that were developed as alternatives to the rational model and that try to address this complexity are the political-bargaining model and the garbage can model. In the political-bargaining model, decisions are the result of bargaining and compromise by participants rather than rational analysis of a problem. When preferences among participants conflict, power determines the outcomes of the process. ${ }^{4}$ In the garbage can model, decisions are not the result of conscious choice, planning, or negotiation, but rather are determined by the timing of events or by chance. Decision making is described as an activity where relatively independent problems, solutions, and participants come together, and may or may not resolve a problem. ${ }^{5}$

The political-bargaining model has been reasonably well developed and is frequently used as a basis for research. ${ }^{6}$ It is both descriptive and prescriptive. While the garbage can model or revisionist model has received considerable attention and is routinely included in standard texts on organizational theory, the model has not been as well developed nor its terms defined. ${ }^{7}$ It is primarily descriptive and does not provide as clear signals for improving the decisionmaking process.

Because the two models have emerged out of dissatisfaction with the rational model, more energy has been spent on distinguishing them from the rational model than from each other. However, the political bargaining and the garbage can models are often hard to distinguish because they encompass many of the same characteristics of organizations and decision makers. As Charles Perrow has argued, many of the case studies used to describe the garbage can model could just as easily be used to illustrate political-bargaining processes. ${ }^{8}$ To clarify the differences, this study begins by presenting an analytical framework that compares the two models. The study then applies both models to a decision-making situation to compare their utility for understanding the decision-making situation. Finally, the study explores the implications and uses of the models.

\section{FRAMEWORK FOR ANALYSIS}

The research on decision making is often presented through comparisons of 
the various models of decision making. 9 Generally, comparisons of decisionmaking models view the process as a series of stages that can be identified and separated. This stage analysis makes the process seem more organized than it is in complex organizations and makes it difficult to distinguish between politicalbargaining and garbage can processes. Furthermore, the descriptions of the garbage can model presented by theorists generally repeat the basic framework described by James G. March, Michael Cohen, and Johan Olsen, but rarely add to or clarify the concepts presented by the originators of the model. ${ }^{10}$

The political-bargaining model views organizations as "alive and screaming political arenas that house a complex variety of individuals and interest groups."

The framework for this study addresses these issues by beginning with concepts within the models rather than stages of the process. It includes three categories of variables based on the criticisms of the rational model: characteristics of the organization, characteristics of the decisionmaking process, and problem-solving methods (the dependent variable). Characteristics of the organization include four variables: degree of ambiguity about goals, from unambiguous to ambiguous; degree of certainty about organizational process, from certain to uncertain; degree of structure in the organization, from structured to unstructured; and adequacy of organizational resources, from excess to scarce. Characteristics of the decision-making process include four variables: interdependence of participants, from interdependent to independent; diffusion of power, from centralized to dispersed; use of information by participants, from used to not used; and participants' perception of the issue, from important to unimportant.

In the next sections, the models are described using this framework. By looking at these different concepts, the framework, then, as summarized in table 1, makes it possible to distinguish the political bargaining and the garbage can models from each other.

\section{POLITICAL-BARGAINING MODEL OF DECISION MAKING}

The political-bargaining model views organizations as "alive and screaming political arenas that house a complex variety of individuals and interest groups." "11 Because an organization is viewed as a coalition of diverse interests, organizations are seen as having multiple, conflicting goals which change as the balance of power changes. In this system, outcomes or decisions are the result of bargaining behavior. Individuals and interest groups enter into bargaining situations in an effort to influence goals and decision making in the system. They continue to bargain only as long as they believe they will benefit from continuing to participate in the process. Individuals do not need to agree on goals and values. They only need to agree to bargain.

\section{Characteristics of the Organization}

The political-bargaining model begins with multiple, conflicting goals for the organization. It assumes that people's behavior is purposeful and based on their objectives, and that individual goals remain consistent throughout the decision-making process. Furthermore, because the decision-making process involves multiple actors with conflicting views, participants are likely to be uncertain as to the connections between their actions and the outcomes of the process.

Still, the political-bargaining model assumes that decision-making processes are intentional rather than random. The organizational structures which exist will preselect players, may determine the player's point of entrance into the game, and may distribute advantages and disadvantages to each group. Organizational rules, players' positions within the hierarchy, and imposed deadlines all help structure the bargaining process. However, the rules apply only to participants in the process. Problems and solutions are not 
TABLE 1

FRAMEWORK FOR ANALYSIS

I. Characteristics of the Organization

A. Process of Goal Definition

1. Well-defined

2. Ill-defined

3. Emerging

B. Degree of Certainty about Organizational Processes
1. Certain
2. Uncertain

C. Degree of Structure in the Organization

1. Structured

2. Unstructured

D. Adequacy of Organizational Resources

1. Scarce

2. Excess

II. Characteristics of the Decision-making Process

A. Degree of Interdependence of Participants

1. Interdependent

2. Independent

B. Diffusion of Power

1. Centralized

2. Dispersed or distributed

C. Use of Information by Participants

1. Gathered and used

2. Gathered but not used

D. Participants' Perception of the Issue

1. Important

2. Unimportant

III. Method by Which the Process Solves Problems

A. Political bargaining model: bargaining until participants are willing to accept a decision

B. Garbage can model: ad hoc process; problems are resolved when participants no longer consider the issue a problem

considered as separate entities in the decision-making process. In addition, resources are assumed to be scarce and participants come into conflict as they seek to maximize their own interests and resources.

\section{Characteristics of the \\ Decision-making Process}

In the political-bargaining model, participants are interdependent. They react to the actions of others and take other participants into account as they plan their own strategies. Managers have to assess power throughout the organization as it is imperative that they accurately diagnose power to use bargaining strategies ranging from coalition building to co-optation successfully.

Information plays an important part in the decision-making process. Information is gathered to help the decision maker in 
assessing alternatives. The political-bargaining model emphasizes the cost of gathering information and recognizes that participants may not seek information on all alternative solutions to a problem. They gather information to support their views and then may use that information in their bargaining process as they try to guess how other participants will respond.

Finally, the political-bargaining model predicts that, if an issue is perceived to be important, then participants will use bargaining tactics, incremental strategies, and coalition building techniques as they try to gain their own objectives within the organization. Negotiation and compromise are likely to occur as participants seek to keep the game of decision making progressing toward a resolution. The issue is resolved at the point that participants agree to accept the decision. However, this may not be a final solution. Because there may be winners and losers in the process, participants who lose in one decision may return to fight the issue another day. In the political-bargaining model, decisions can be reconsidered if participants choose to continue to pursue the issue.

In summary, the political-bargaining model views the decision-making process as a bargaining game where individuals pursue their own interests within the organization, but do so by taking others into account. Conflict is legitimate as individuals have different objectives and different amounts of power to pursue their goals. Participants' behavior is purposeful. The organization, however, may not appear as such because participants simultaneously pursue multiple, conflicting goals.

\section{GARBAGE CAN MODEL OF DECISION MAKING}

March, Cohen, and Olsen have developed a model of decision making known as the garbage can model to describe decision-making processes in organizations that are characterized by ambiguity. Although classical theories of choice, which assume that goals and objectives are the basis for action, proved unable to explain the confusion that actually goes on in complex organizations, garbage can studies present a picture of decision making that seems pathological when compared to those assumed by classical theories. ${ }^{12}$ Problems appear in various parts of the organization and then disappear without being resolved. Managers spend time making decisions that are not implemented. Participants drop in and out of the decision-making process, seeming to appear at random in decision-making opportunities.

\section{Characteristics of the Organization}

The garbage can model begins with the assumption that an organization's goals are problematic or ambiguous. Unlike the political-bargaining model, objectives may also be ill-defined or inconsistent for individual decision makers. Individuals are, in fact, often uncertain about how organizational processes function. As a result, the links between problems, solutions, and people are not always clear. Decision makers find that the outcomes of decisionmaking opportunities are only loosely connected to the decision-making process. Although organizational structures or rules and regulations help determine how problems, solutions, and participants can be linked, in loosely structured organizations, that initial linking of problems and participants does not guarantee that problems, solutions, and participants will remain stable, consistent, or linked throughout the process.

Furthermore, the amount of resources in the organization affects the number of decision-making opportunities. When there are excess resources, managers can create enough decision-making opportunities to satisfy everyone who wants to participate in the decision-making process. When resources are scarce, not all demands will be met. "Political-bargaining strategies are likely to be employed by participants, and power can take the place of contextual or chance factors in the decision-making situation." ${ }^{13}$

\section{Characteristics of the \\ Decision-making Process}

Participants function independently of each other as they choose to attend 
various decision-making opportunities. Problems, solutions, or participants may adjust, change, or react independently and are not likely to be stable throughout the process. Therefore, participants have limited ability to influence the outcome of the decision-making process, and there can be a lot of discontinuity. Information may be gathered and not used when participants find themselves addressing different problems as the decision-making process develops.

\section{Both the political-bargaining model and the garbage can model provide librarians with ideas on how to successfully manage the decision-making process.}

Garbage can processes are apt to be most evident when organizations have to deal with issues that are perceived to be important. The reason is that important decisions attract a large number of participants, problems, and solutions, and typically address the problems of scarce resources and those that involve highly emotional, powerful, symbolically visible, or technically fuzzy issues. ${ }^{14}$

In summary, the garbage can model captures the complex environment that surrounds organizational decision making. It does not concentrate on one or two major concepts to explain decision making, but assumes that there are numerous explanatory variables that may affect the process. The model includes the wide range of confusing events that impinge on the process but which are not covered in other models of decision making. The strength of the model is its ability to account for much of the apparently random behavior that is observed in organizations. It is intuitively satisfying because it brings a level of understanding to organizational behavior that has not been well covered in other models.

Therefore, the political-bargaining model and the garbage can model share some of the same characteristics (see table 2). There are, however, important differences between them. Specifically, the garbage can model emphasizes illdefined goals for individuals and the independence of the participants in the process, while the political-bargaining model stresses multiple goals only for the organization and the interdependence of the participants.

The next step in the research was to apply the two models to a decisionmaking situation to determine if the distinctions provided by this framework, particularly for the variables of goal definition and degree of independence of participants, were significant enough to distinguish garbage can processes from political-bargaining processes.

\section{RESEARCH METHODS}

To examine the two models, each model was used to study a decision about the best system for governing a university library. ${ }^{15}$ To conduct the research in studying the decision-making process, it seemed appropriate to use a case study method along with participant observation. ${ }^{16}$ By being part of the process, one is better able to describe the context of the decisionmaking process, to identify the intentions of participants in the process, and to trace problems, solutions, and participants in the process. The problems and difficulties associated with the case study method and one participant observer recording and interpreting events are acknowledged. ${ }^{17}$ Although the process allows for a detailed description of the observed culture or organization, the observer must be aware of the possibility that participants may change their behavior if they know they are being observed, may be influenced by the researcher, or may try to misdirect the observer. ${ }^{18}$ Because the author was familiar with the organization chosen for the case study, the author was in a position to try to evaluate if the actions of participants were consistent with their behavior in other decision-making situations. Furthermore, whenever possible, informal interviews and documentation were used to support or deny the author's interpretations.

\section{Data Collection}

Information about the decision-making process was obtained in four ways: 
TABLE 2

COMPARISON OF THE RATIONAL, POLITICAL BARGAINING AND GARBAGE CAN MODELS

\begin{tabular}{|c|c|c|c|}
\hline \multicolumn{4}{|c|}{ Characteristics of Organization } \\
\hline Variable & Rational & Political Bargaining & Garbage Can \\
\hline Goals & $\begin{array}{l}\text { Well-defined; } \\
\text { consistent }\end{array}$ & $\begin{array}{l}\text { Goals are known but } \\
\text { may differ among } \\
\text { participants } \\
\text { consistent for } \\
\text { individual }\end{array}$ & $\begin{array}{l}\text { Ill-defined, may } \\
\text { emerge at any time }\end{array}$ \\
\hline Degree of certainty & Assumes certainty & $\begin{array}{l}\text { High degree of } \\
\text { uncertainty }\end{array}$ & $\begin{array}{l}\text { High degree of } \\
\text { uncertainty }\end{array}$ \\
\hline Degree of structure & Highly structured & $\begin{array}{l}\text { Structure defines } \\
\text { particular roles }\end{array}$ & $\begin{array}{l}\text { May be unstructured } \\
\text { or partially } \\
\text { structured }\end{array}$ \\
\hline Adequacy of resources & Assumed adequate & Scarce & Excess or scarce \\
\hline \multicolumn{4}{|c|}{ Characteristics of Decision-making Process } \\
\hline Variable & Rational & Political Bargaining & Garbage Can \\
\hline $\begin{array}{l}\text { Degree of } \\
\text { interdependency }\end{array}$ & Roles are defined & Interdependent & Independent \\
\hline Diffusion of power & $\begin{array}{l}\text { Authority is part of } \\
\text { bureaucratic } \\
\text { structure }\end{array}$ & Dispersed & Dispersed \\
\hline Use of information & Gathered and used & Gathered and used & $\begin{array}{l}\text { Gathered, used } \\
\text { or not used }\end{array}$ \\
\hline Perception of issue & $\begin{array}{l}\text { May be important } \\
\text { or unimportant }\end{array}$ & Important & Important \\
\hline $\begin{array}{l}\text { Method of solving } \\
\text { problems }\end{array}$ & Value-maximization & $\begin{array}{l}\text { Bargaining, coalition } \\
\text { building }\end{array}$ & Ad hoc \\
\hline
\end{tabular}

direct participant observation as a member of the library faculty, interviews with participants throughout the decision-making process, examination of minutes of meetings and documents related to the process, and interviews with key participants involved in the process after the governance document was completed.

Interviews were particularly important. During the decision-making process, informal interviews were conducted with most participants in the process. Throughout the process, two main questions were asked. First, participants were asked if they believed the decision-making process was progressing, and if their concerns were being addressed. Second, participants were asked what other activities were important to them in addition to the governance decision-making process.

Upon the conclusion of the decisionmaking process, formal interviews were conducted with the major participants. The participants were interviewed over a six-month period to determine how they saw the process once it was completed. They were asked open-ended questions, such as: How do you feel about the process? Do you believe the process adequately addressed the issues? What problems do you think we were trying to solve? What incidents stand out as significant? What other activities were you involved in during the process?

Follow-up interviews were conducted with participants when clarification was needed. The information gathered from 
the interviews was supplemented by data gathered from written documents, minutes of meetings, and university and library publications. Data from the notes, minutes, and documents were used to verify and correct the recollections of participants and to identify actions that fit into the official chronology of events.

\section{Case Study: Applying the Models to a Decision about University Governance}

A university committee charged with designing a governance system for the library worked for a year and a half to design a system that would "provide for procedures of due process (regarding employment issues for librarians) and would establish a mechanism by which the Library Director could consult with the professional librarians on matters concerning the quality and development of the library program and staff." 19

The issue was important for the librarians because it involved their employment status and established procedures for the evaluation and promotion of the professional librarians. Four groups were active in the decision process. The university's administration was represented on the committee by the associate vice-chancellor for academic affairs. The administration felt that the librarians should change their current system of governance so that it provided some job security for the librarians but eliminated the current tenure system for librarians. The library director, who served on the committee, also favored eliminating tenure for librarians and wanted the director to have more input into promotion and evaluation decisions.

Two librarians also served on the governance committee and were responsible for representing the views of the librarians and for conveying the librarians' concerns to the administration. Representation proved to be a difficult task, however, as the broader set of librarians did not have a common objective in the process and as factions emerged among them as the process developed. A minority group of librarians held that librarians should retain their current tenure system. This group formed early in the process and consistently held to their views.
They were unwilling to compromise with the administration and argued that the administration did not offer any proposals that were better than the tenure system. Most of the librarians, on the other hand, did not hold firmly to any particular viewpoint. At first, they supported a modified tenure proposal, a proposal rejected by the administration early in the process. As the debates continued over a period of months, the majority of librarians failed to come to a firm consensus on what type of system they wanted. As time passed, the librarians became involved in other projects in the library and devoted less and less time to the governance debate. Some librarians who were active in the beginning of the process and then moved on to other issues returned to the governance debates near the end of the process. These librarians tried to reintroduce their concerns into the debates as if the topics under discussion had not changed in their absence.

\section{Although the decision-making process} allows for a detailed description of the observed culture or organization, the observer must be aware of the possibility that participants may change their behavior if they know they are being observed, may be influenced by the researcher, or may try to misdirect the observer

In the meantime, the two librarians on the governance committee attempted to survey the librarians a number of times for input. Each vote yielded a different result. Sometimes the librarians favored tenure, and sometimes they favored multiyear contracts. In the end, the librarians on the committee supported the university administration and the library director, proposing for the librarians a multiyear contract system that offered some job security to the librarians but denied them tenure. The majority of the librarians accepted this proposal with little debate on the merits of the system and without resolving the conflicts with 
the minority group of librarians. The minority group continued to oppose the proposal, sought legal assistance, and spent their energy trying to have the decision changed, but were unable to persuade the other participants in the process to accept their viewpoint.

\section{DISCUSSION OF THE CASE STUDY}

The framework for the analysis did prove to be a useful way to distinguish between political-bargaining and garbage can processes in the case study. The political-bargaining model successfully describes the actions of the minority group of librarians and the university administration. Both groups had consistent goals and engaged in bargaining tactics in an effort to achieve their primary objectives. The model also predicts that groups will seek to maintain or increase their power and that the eventual decision will reflect the positions of those with the most power. The administration, which was seen as the group with the most power, achieved its primary objective of creating a different governance process for the librarians. The minority group was unsuccessful in its attempt to increase its power by seeking legal assistance in its efforts to keep its limited tenure system as an option for the current library faculty. Nevertheless, the model does not explain or predict the rather inconsistent behavior of the majority of the librarians who held no firm opinions on the governance issues.

The garbage can model, on the other hand, accurately describes the random actions of the majority of the librarians. The librarians drifted through the process, first supporting the current tenure system, and then moving to multiyear contracts without carefully considering the alternatives or thinking through their positions. They did not try to develop coalitions or to amass support for a particular position. Individually, they changed their stances on the issues, inconsistently voting for one position one week, and another position the next. Others in the process could not count on their continued support for any particular proposal. Furthermore, individuals who felt strongly about the issues in the beginning were distracted by other events, as the debates continued. Some librarians who initially argued passionately for a particular point of view, later dropped out of the process, then reappeared at the end of the debates when other events had lost their attention. These individuals then tried to argue for a variety of viewpoints without considering the changes that had occurred in their absence.

The librarians attended library faculty meetings about the governance issue until they found something else to do. They moved on to new issues without resolving the problems in the governance process. Too, they raised unrelated issues in the governance debates whenever something caught their attention. As a consequence of this behavior, the governance meetings included debates about performance appraisal forms, personnel evaluation systems outside of tenure issues, and affirmative action regulations. The garbage can model accounts for these diverse debates by noting that problems can appear in unrelated decision-making opportunities and that participants will use whatever opportunities are available to them to discuss concerns.

\section{CONCLUSIONS}

\section{Utility of the Models}

One conclusion of the case study was the demonstration that political-bargaining and garbage can processes can exist in the same decision-making situation and managers can use the framework presented here to distinguish between the different approaches. Once managers are able to identify the approach most likely to be taken by participants, they can alter their own strategies to affect the outcome of the process. That is, managers can seek to adjust their strategies to influence other participants.

When political-bargaining behavior is evident, participants can view the decision-making process as a game of winners and losers, and develop strategies for trying to maximize their own gains in the process. Strategies that have been developed to help decision makers 
manage political-bargaining processes include game theory, bargaining tactics, satisficing strategies, and incremental strategies. ${ }^{20}$ As Charles Lindblom noted, these strategies allow for pluralistic interests in complex organizations. ${ }^{21}$

To identify garbage can processes and to let go of the rational imperative, managers can ask themselves the following types of questions. Are unrelated problems being discussed at decisionmaking opportunities as if the problems were related? Do solutions appear on agendas before problems have been discussed? Do participants attend all meetings or is their attendance sporadic? Do participants say that meetings are important, but still fail to attend? These types of questions begin to explore the concepts that are part of the garbage can model and may help managers to recognize the independence of participants, problems, and solutions.

\section{When political-bargaining behavior is evident, participants can view the decision-making process as a game of winners and losers, and develop strategies for trying to maximize their own gains in the process.}

Once managers recognize that a decision-making process resembles the garbage can model, they have at least three possible responses: add controls, adapt to the process, or embrace the process. ${ }^{22}$ In the first strategy, managers can try to add structure, rules, or regulations to the decision-making process to limit the movement of problems, solutions, and participants throughout the process. In the second strategy, managers adapt their own style to maximize their ability to influence the decision-making process. Tactics such as setting deadlines, spending a lot of time on a problem, and persisting with an issue can all affect the overall process. Further, managers can try to affect the timing of events by overloading the system with problems. This tactic should distract participants from some of the issues so that the manager is more likely to be able to pursue his or her own agenda. Finally, as a third strategy, managers can embrace the process and increase flexibility in the organization. Managers may suspend rules and encourage participants to act first and think later in an effort to bring creativity into the decision-making process. ${ }^{23}$

Of course, managers will need to combine a variety of strategies to be effective in this ambiguous environment. For example, they can use bargaining strategies, negotiation, and coalition building techniques with those participants following a political-bargaining strategy. These strategies are not likely to be effective, however, with participants who have ill-defined goals and are acting independently of each other. For these individuals, managers should switch tactics. Here setting controls, establishing deadlines, and overloading the system with problems may be effective in allowing the manager to influence the outcome of the decision-making process. Furthermore, although such strategies as spending time on an issue and persisting with an issue can be effective in both political-bargaining and garbage can processes, this is not true for most tactics. For example, a tactic such as overloading the system with problems in order to distract participants, which can work in the garbage can model, is not likely to be effective in the politicalbargaining situation. This is because participants who are dedicated to a cause are apt to ignore other issues and concentrate on their major agenda. The manager, then, needs to recognize this dedication and adopt strategies to work effectively with such groups.

In summary, both the political-bargaining model and the garbage can model provide librarians with ideas on how to successfully manage the decision-making process. While the political-bargaining model prescribes betterorganizationalstructures to use to understand, manage, and improve the decision-making process, the garbage can model emphasizes the important role of the manager in understanding the decision-making process. By concentrating on organizational processes rather 
than on organizational structures, the garbage can model gives a more complete picture or description of the complexities of the decision-making process. It provides managers with clues as to how to function effectively in times of organizational change and under conditions that seem chaotic. By using the framework for analysis presented here, managers can begin to distinguish between the two approaches and can become more successful at identifying appropriate strategies to use to influence the outcomes of decisionmaking processes.

\section{REFERENCES AND NOTES}

1. James Burns, Leadership (New York: Harper \& Row, 1978), 379.

2. For example see Charles Perrow, Complex Organizations (New York: Random, 1986) and Herbert Simon, Administrative Behavior (New York: Free Pr., 1976).

3. For example, see Morgan McCall and Robert Kaplan, Whatever It Takes: Decision Makers at Work (New York: Prentice Hall, 1985) and John Kingdon, Agenda, Alternative, and Public Policies (Boston: Little, 1984).

4. Jeffrey Pfeffer, Power in Organizations (Marshfield, Mass.: Pitman, 1981), 28.

5. Ibid., 26.

6. Graham Allison, "Conceptual Models and the Cuban Missile Crisis," American Political Science Review 63 (1969): 689-718; Victor Baldridge, Power and Conflict in the University (New York: Wiley, 1971); Lee Bolman and Terrence Deal, Modern Approaches to Understanding and Managing Organizations (San Francisco: Jossey-Bass, 1984); Richard Cyert and James G. March, A Behavorial Theory of the Firm (New York: Prentice Hall, 1983); Charles Lindblom, "Science of Muddling Through," Public Administration Review 19 (1959): 79-88; Jeffrey Pfeffer, Power in Organizations; Simon, Administrative Behavior.

7. Michael Cohen, James G. March, and Johan Olsen, "A Garbage Can Model of Organizational Choice," Administrative Science Quarterly 17 (1972): 1-19.

8. Charles Perrow, "Ambiguity and Choice in Organization," Contemporary Sociology: A Journal of Reviews 63 (1977): 294-98.

9. For example, the classic work by Graham Allison (see note 6) provides a comparison of three models of decision making, including the rational model, the bureaucratic model, and the political-bargaining model. Bolman and Deal (1984) use four major categories: rational, human relations, political, and symbolic in their work on understanding decision making in organizations. Jeffrey Pfeffer (1981) details the politicalbargaining model, and provides brief descriptions of the rational, bureaucratic, and garbage can models. Lawrence Pinfield (1986) divides the decision-making models into structured and unstructured models and compares the characteristics of these two broad categories of models. Anne Grandori (1984) compares various strategies of decision making on the two fundamental dimensions of uncertainty and conflict of interest.

10. Cohen et al., "A Garbage Can Model of Organizational Choice."

11. Bolman and Deal, Modern Approaches to Understanding and Managing Organization, 250.

12. McCall and Kaplan, Whatever It Takes: Decision Makers at Work, xi.

13. Michael Moch and Louis Pondy, "Structure of Chaos: Organized Anarchy as a Response to Ambiguity," Administrative Science Quarterly 22 (1977): 357.

14. Bolman and Deal, Modern Approaches to Understanding and Managing Organizations, 250.

15. The identity of the university for this case and the identity of the participants have been masked to maintain the confidentiality of the interviews.

16. A pilot study was conducted as part of the full research, and revisions were made in the framework and in the methodology to resolve problems identified in the pretest.

17. For a more complete analysis of the limitations associated with this methodology, see Joan R. Giesecke, Making Decisions under Chaotic Conditions (Ann Arbor, Mich.: University Microfilms, 1988).

18. Earl Babbie, Practice of Social Research (Belmont, Calif.: Wadsworth Publishing, 1983) and Clifford Geetz, Interpretation of Cultures (Newbury Parks, Calif.: Sage, 1983).

19. Vice Chancellor, memo to Library Director, 1985. 
20. For further information about political-bargaining strategies, see Baldridge, Power and Conflict in the University; Bolman and Deal, Modern Approaches to Understanding and Managing Organizations; Anna Grandori, "A Prescriptive Contingency View of Organizations," Administrative Science Quarterly 29 (1984): 192-209; Lindblom, "Science of Muddling Through"; Pfeffer, Power in Organizations.

21. Lindblom, "Science of Muddling Through," 81-83.

22. James G. March and Roger Weissinger-Baylon, Ambiguity and Command (Marshfield, Mass.: Pitman, 1986), 23-24.

23. James G. March and Johann Olsen, Ambiguity and Choice in Organizations (Bergen: Universitetsforlaget, 1979), 78-79.

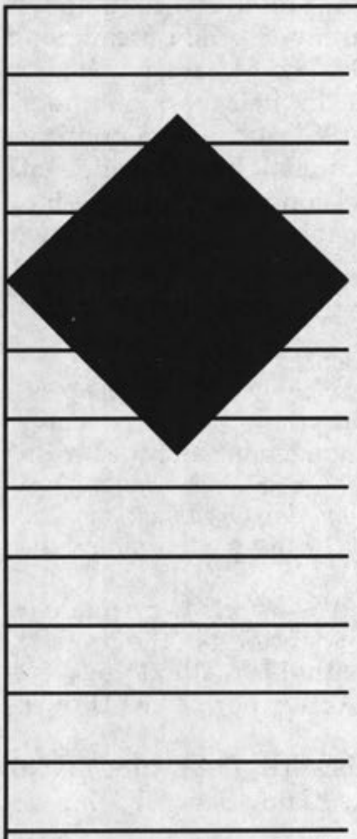

\section{OCLC/AMIGOS Collection Analysis Systems}

Make a wise investment. Choose from three options

to analyze your library's data:

Collection Analysis CD compares quantitative data

BCL3 Tape Match measures against a standard

Tape Analysis fits individual specifications

Available exclusively from AMIGOS Bibliographic Council, Inc. 12200 Park Central Drive, Suite 500

Dallas, Texas 75251 